\title{
Adventures in Music Translation: Italian Songs and Arias (aka "The Yellow Book") and Me
}

\author{
Lynn Penrod \\ University of Alberta, Edmonton
}

This article is a general exploration of translation issues involved in the translation and performance of the art song, arguing that although critical interest in recent years has been growing, the problems involved in these hybrid translation projects involving both text and music present a number of conundrums: primacy of text or music, focus on performability, and age-old arguments about fidelity and/or foreignization vs domestication. Using information from theatre translation and input from singers themselves, the author argues that this particular area of translation studies will work best in the future with a collaborative approach that includes translators, musicologists, and performers working together in order to produce the most "singable" text as possible for the art song in performance. 